\title{
Anti-IL-23 exerted protective effects on cerebral ischemia-reperfusion injury through JAK2/STAT3 signaling pathway
}

\section{Lichao Fan}

Beijing Chaoyang Hospital

Lichun Zhou ( $\square$ lichunzhoucyyy@163.com )

Beijing Chaoyang Hospital https://orcid.org/0000-0002-6935-1250

\section{Research}

Keywords: anti-IL-23, cerebral ischemia-reperfusion injury, JAK/STAT pathway

Posted Date: June 5th, 2020

DOl: https://doi.org/10.21203/rs.3.rs-30010/v2

License: (c) (i) This work is licensed under a Creative Commons Attribution 4.0 International License. Read Full License

Version of Record: A version of this preprint was published at Molecular Biology Reports on April 1st, 2021. See the published version at https://doi.org/10.1007/s11033-021-06339-4. 
The authors have withdrawn this preprint from Research Square 